3 Exploring the origin of insect wings from an evo-devo

\title{
4 perspective
}

5 Courtney M. Clark-Hachtel and Yoshinori Tomoyasu

6 Miami University, Pearson Hall, 700E High St, Oxford, OH 45056, USA

$7 \quad$ Corresponding author: Tomoyasu, Yoshinori (tomoyay@miamioh.edu)

8 
9 Although insect wings are often used as an example of morphological novelty, the origin

10 of insect wings remains a mystery and is regarded as a major conundrum in biology.

11 Over a century of debates and observations have culminated in two prominent

12 hypotheses on the origin of insect wings: the tergal hypothesis and the pleural

13 hypothesis. However, despite accumulating efforts to unveil the origin of insect wings,

14 neither hypothesis has been able to surpass the other. Recent investigations using the

15 evolutionary developmental biology (evo-devo) approach have started shedding new

16 light on this century-long debate. Here, we review these evo-devo studies and discuss

17 how their findings may support a dual origin of insect wings, which could unify the two

18 major hypotheses.

19 


\section{Introduction}

21 Insects compose nearly $80 \%$ of all known animal species, making them one of the most diverse

22 metazoan groups [1]. The success of this group can partially be credited to the acquisition and

23 subsequent diversification of wing structures [1,2]. However, despite accumulating efforts to

24 unveil the origin of this novel structure (including morphological, taxonomical, and

25 paleontological analyses), the origin of insect wings remains a mystery and is regarded as a

26 major conundrum in biology. The difficulty in deciphering the origin of the insect wing stems

27 from the lack of transitional fossils between apterygote (non-winged) and pterygote (winged)

28 insects in the fossil record [3-6]. The earliest known insect fossils (apterygotes) date from the

29 lower Devonian (390 million years ago, MYA) $[4,5,7,8]$. Although there is no fossil record of the

30 event, insect wings are believed to have evolved only once (i.e. are monophyletic) sometime

31 during the upper Devonian or Lower Carboniferous (370-330 MYA) [3,5,9]. By the early

32 Permian ( 300 MYA), winged insects had diversified into at least 10 orders [4]. Therefore, there

33 is quite a large gap in the fossil record between apterygote and diverged pterygote lineages,

34 which has resulted in a long-running debate over where insect wings have come from and how

35 they have evolved.

37 Two proposed wing origins

38 The insect wing origin debate can be broken into two main groups of thought; wings evolved

39 from the tergum of ancestral insects or wings evolved from the pleuron-associated structures

40 (Figure 1. See Box 1 for insect anatomy) [10]. The tergal origin hypothesis (a.k.a. Paranotal

41 hypothesis) proposes that wings evolved from lateral extensions of the thoracic tergum, allowing

42 ancient insects to glide and, when eventually articulated, to fly (Blue in Figure 1) [11-13]. The 
43 pleural origin hypothesis has many variations, but essentially proposes that wings formed from

44 an outgrowth and/or branch of pleural tissue (yellow in Figure 1). Depending on the variation of

45 this hypothesis, the proposed origin can be a de novo projection of the pleural plate or the

46 articulated branches (exites and/or endites) that stemmed from the pleural plate. An influential

47 variation of the pleural hypothesis is the exite hypothesis, which states that insect wings

48 originated from exites of ancestral proximal leg segments (such as epicoxa) (Figure 1) [14,15].

49 According to this hypothesis, the exites migrated dorsally and flattened to eventually become the

50 wing blade recognized today $[13,14,16]$, while ancestral proximal leg segments fused into the

51 body wall and provided a series of sclerotized plates along with preexisting muscle attachment,

52 enabling the quick acquisition of insect wing articulation [14].

\section{Application of evo-devo to insect wing origin studies}

55 As mentioned earlier, difficulty in revealing the origin of insect wings stems from the lack of

56 transitional fossils between apterygotes and pterygotes. The absence of "proto-wings" in the

57 fossil record has necessitated the search for wing serial homologs in wingless segments (such as

58 T1 or abdominal segments) of winged insects or wing homologs in wingless species (apterygotes

59 and non-insect arthropods), in hopes that they will provide clues to the transitional state in the

60 evolution of insect wings (Box 2). The tergal lobe of silverfish (apterygotes), T1 pronotal lobes

61 of several extant insect species (such as mantises and cockroaches), and the T1 winglet of

62 Palaeodictyoptera (an extinct palaeopteran order), have been proposed to be wing (serial)

63 homologs in support of the paranotal hypothesis (Figure 2) [10,17]. In contrast, the abdominal

64 gills/gill plates in palaeopteran nymphs and the leg branches in apterygotes and other non-insect

65 arthropods (such as bristletail styli and crustacean endites/exites) have been proposed to be 
66 homologous to wings in support of the pleural origin hypothesis (Figure 2) (reviewed in [16]).

67 However, all of these proposed wing homologs (both tergal and pleural) are morphologically

68 quite distinct from the actual wing, making it difficult to argue that any of these tissues reflects a

69 transitional state in the evolution of wings.

70 Only recently have we been able to use the combination of molecular and developmental

71 approaches (i.e. evo-devo) to investigate questions related to the origin of insect wings. The

72 accumulated knowledge on genes and pathways involved in insect wing development (mainly

73 from Drosophila studies) opens the possibility of identifying wing homologs without relying on

74 morphology, providing us with a new angle to tackle this century-long conundrum. In fact, the

75 main switch in popular opinion from a tergal to a pleural origin of wings in the late 1900's came

76 with the advent of molecular tools. Averof and Cohen discovered that the critical wing genes

77 apterous (ap) and nubbin (nub) are expressed in the exites of the brine shrimp (Figure 2) [18]. In

78 Drosophila, ap is expressed in the dorsal compartment of the wing primordium [19], while nub

79 is expressed in the entire developing wing [20]. Therefore, the expression of these genes in the

80 exites of the brine shrimp provided the first molecular support for the homology between

81 crustacean exites and insect wings. As the first molecular evidence, this finding was quite

82 influential on popular opinion at the time (Box 2). This study illuminates the potential impact

83 that the evo-devo approach can have on the insect wing origin debate.

84

\section{Dual origin hypothesis supported by an evo-devo study}

86 In 2010, Niwa et al. reported their expression analyses of several wing genes in two basal insect

87 orders, Archaeognatha (bristletails) and Ephemeroptera (mayflies) [21]. They found that both the

88 tergal margin and pleural branches (stylus of bristletails and abdominal gill of mayflies) share a 
89 part of the wing gene network operating during Drosophila wing development (Figure 2).

90 Through this finding, they proposed that the fusion of these two fields facilitated the evolution of

91 the insect wing, thus suggesting a dual origin of insect wings.

92 Although this is the first time a dual origin was proposed from the evo-devo perspective, this

93 type of combinational model (i.e. dual origin hypothesis) has been proposed in the past (Figure

94 1). Crampton may be the first to mention the possibility of the combinational model, although he

95 was in favor of the paranotal hypothesis [17]. Later, Rasnitsyn proposed that the wing originated

96 from the fusion of notal lobes and proximal leg segments (coxopodite) [11]. Nonetheless, Niwa

97 et al. provide an important turning point in the insect wing origin debate by hinting at the

98 possibility of unifying the two hypotheses on insect wing origin based upon molecular evidence.

99

100 Two distinct T1 wing serial homologs identified through evo-devo

101 analyses

102 Our previous work provided another important piece of evidence in support of a dual origin

103 hypothesis. Through the functional analysis of vestigial ( $\mathrm{vg}$ ), a critical wing gene, we found that

104 there are two $v g$-dependent tissues in the "wingless" T1 of the Tribolium beetle (the carinated

105 margin and two pleural plates) (Figure 2) [22]. $v g$ is known as the wing master gene due to its

106 ability to induce wings in non-wing contexts when ectopically expressed (with some limitations)

$107[23,24]$. The ectodermal function of $v g$ appears to be specific to wing formation (at least in

108 Drosophila), making this gene an interesting candidate for the identification of wing-related

109 structures.

110 The identification of two $v g$-dependent tissues in the T1 segment of Tribolium was quite 111 surprising because it is generally assumed that wing-related tissues are never induced in T1 of 
112 most (if not all) insects. Interestingly, the only vg-dependent tissues we identified in T2 and T3

113 were the wings (except for a small region at the base of the T3 leg), suggesting that the T1 vg-

114 dependent tissues may be serially homologous to the wings on T2 and T3.

115 The serial homology between the T1 vg-dependent tissues and the wing is further

116 supported by analysis of homeotic transformations. In insects, segmental identities are

117 determined by a cluster of genes, called Hox genes (reviewed in [25]). Serially homologous but

118 distinct structures are often produced by the action of Hox genes (such as with wings and

119 halteres in flies [26,27], also see Box 3). In T1, a Hox gene, Sex combs reduced (Scr), has been

120 shown to repress wing development [28,29]. We found that reducing Scr function in Tribolium

121 leads to the merger of the two vg-dependent tissues and the transformation of the merged tissues

122 into an ectopic wing, strongly suggesting that these two $v g$-dependent tissues are wing serial

123 homologs in T1 (Figure 2) [22].

124 Intriguingly, these two tissues appear to be homologous to the two proposed wing origins

125 (Figure 2). The carinated margin is tergal in nature and therefore can be related to the

126 tergal/paranotal lobe hypothesis. In contrast, the two pleural plates can be related to the

127 pleural/exite hypothesis. Therefore, the two T1 vg-dependent tissues could be wing serial

128 homologs present in (or reverted to) a more ancestral state, and their merger to form a complete

129 wing upon homeotic transformation provides compelling functional evidence for the dual origin

130 of insect wings.

\section{Abdominal vg-dependent wing serial homologs in beetles}

133 Ohde et al. also found that there are $v g$-dependent tissues in $\mathrm{T} 1$ as well as in other non-winged

134 segments of the Tenebrio beetle [30]. The hypomeron in the T1 segment identified as $v g$ - 
135 dependent in this study corresponds to the carinated margin in our study (the carinated margin is

136 a part of the hypomeron [22]). Additionally, they found that defensive structures in the pupal

137 abdomen, called gin traps, are also vg-dependent. Further analysis of homeotic transformations

138 led them to propose that gin traps are wing serial homologs in the abdominal segments (Figure

139 2). This study along with our own led to the realization that wing serial homologs in the wingless

140 segments are more common than initially anticipated and also signifies the potential usefulness

141 of identifying $v g$-dependent tissues to reveal wing serial homologs in other insects.

143 Treehopper helmets: "partial” wing serial homologs?

144 Prior to the previous two studies in beetles, Prud'homme et al. found that treehopper helmets

145 have high $n u b$ expression and proposed that these impressively exaggerated structures are

146 modified wings of the T1 segment (Figure 2) [31]. Unfortunately, this report was disputed rather

147 intensely due to errors in their morphological interpretation [32,33]. Further morphological

148 analyses have revealed that the treehopper helmet is an extreme posterior expansion of T1

149 tergum and not an appendage on T1 [32,33]. As we discussed in our previous report [22], the

150 recognition of the two wing serial homologs in T1 of Tribolium may provide an alternative

151 explanation for the identity of the treehopper helmet. Since both the treehopper helmet and the

152 beetle carinated margin are an expansion of T1 tergum, it is likely that these two tissues are

153 homologous, suggesting the possibility that the treehopper helmet is not an appendage, yet may

154 be serially homologous to a part of the wing (i.e. partially serially homologous to the wing).

155 This treehopper helmet discussion offers an interesting (and perhaps rather thought

156 provoking) view to the insect wing origin debate; the wing serial homologs in wingless segments

157 may be more widespread among insects than initially anticipated. In 1916, Crampton suggested 
158 that pronotal expansions seen in various insects (such as silverfish, mantises, hemipterans, and

159 several more species) could be wing serial homologs [17] (and more insects are mentioned in

$160[10]$ ). We propose that most (if not all) tergal margins may actually be "partially" serially

161 homologous to the wing (i.e. to the portion that is tergal in origin). A comprehensive survey for

162 wing serial homologs in various insects through an evo-devo approach will shed light on the

163 widespread occurrence of wing serial homologs in the wingless segments of insects.

164

\section{An evo-devo based dual origin hypothesis}

166 Two important insights obtained from evo-devo studies to date on the origin of insect wings are

167 (i) a possible widespread nature of wing serial homologs in the wingless segments, and (ii) the

168 presence of two distinct types of tissues individually serially homologous to a part of the wing

169 (tergal and pleural). Another critical observation we made in our previous study is that the tergal

170 and pleural wing serial homologs in T1 merge to form a complete wing upon homeotic

171 transformation in Tribolium [22]. Together, these findings allow us to revise the dual origin

172 hypothesis from an evo-devo perspective, namely, insect wings have a dual origin, and the

173 merger of two unrelated tissues (dorsal and pleural) was a key step in developing this

174 morphologically novel structure during evolution. In this hypothesis, we support and expand the

175 idea that was initially put forward by Niwa et al. [21]; that tergal expansion has provided a

176 genetic mechanism responsible for a large and flat wing blade structure, while pleural plates

177 (potentially with exite-like branches) have provided a complex articulation mechanism along

178 with muscle attachment.

179 The dual origin hypothesis unifies the two major hypotheses by overcoming some

180 limitations of each hypothesis. For example, the acquisition of a complex articulation mechanism 
181 has been difficult to explain by the paranotal hypothesis, but this can be explained by a

182 coxopodite segment (possibly bearing exites) merging into the tergal expansion. On the other

183 hand, the striking similarities between wings and pronotal expansions in some insects (such as

184 vein-like structures in lace bugs) have been used to argue against a pleural origin of insect wings.

185 However, the dual origin hypothesis allows for a pleural contribution to the wing while

186 maintaining the similarities between lobes and wings.

187 A possible genetic mechanism that facilitated the fusion of tergal and pleural tissues is

188 largely unknown. The fusion of the proximal coxopodites into the body wall (i.e. the formation

189 of the pleural plates) that occurred early in the hexapod lineage could have been a key step in

190 placing the two distinct $v g$-dependent tissues in close proximity. Subsequently, the induction of

191 two $v g$-dependent tissues adjacent to each other may have caused a "cross-wiring" of the two

192 distinct developmental pathways, resulting in one fused $v g$-dependent tissue, namely a wing. It is

193 worth mentioning that we have detected two distinct $v g$-positive cell populations in all three

194 thoracic segments during embryogenesis in Tribolium [22]. This observation suggests that the

195 two types of wing serial homologs are initially induced separately even in the winged segments

196 (T2 and T3) of extant insects (i.e. partial recapitulation of phylogeny in ontogeny). An in-depth

197 analysis on how the two distinct $v g$-positive cell populations induced during embryogenesis

198 contribute to the wing imaginal tissues in Tribolium may help us understand how the merger

199 occurred during the evolution of insect wings.

200

201 Testing the dual origin hypothesis

202 Identification of wing serial homologs based on morphological analysis has been the main

203 approach in the attempt to elucidate the origin of insect wings. However, this approach can 
204 detect tissues potentially homologous to wings only when these tissues resemble wings. As

205 described above, identifying $v g$-dependent ectodermal tissues appears to be an effective

206 alternative way to find wing serial homologs, regardless of their morphological similarity to

207 wings. Comprehensive identification of $v g$-dependent tissues throughout insect taxa will provide

208 further clues to the identity and nature of these tissues and how these tissues (or more precisely,

209 the tissues in the winged segments that are homologous to them) have contributed to the

210 evolution of wings. A quick survey of $v g$ orthologs in publicly available insect genome

211 sequences revealed that $v g$ is conserved throughout arthropod taxa (Clark-Hachtel and Tomoyasu,

212 unpublished data). Thus, a survey of $v g$-dependent tissues via expression and/or functional

213 analyses should be applicable to many insect species and possibly even to non-insect arthropods,

214 such as crustaceans.

215 The dual origin hypothesis will be supported if we find two distinct sets of $v g$-positive

216 cells, one in the tergum and the other in the pleuron, in a diverse array of insects. It is also

217 important that these serial homologs are present in some of the wingless segments (such as T1),

218 but not in the winged segments (T2 and T3), as the wings in these segments should correspond to

219 the two wing serial homologs in the wingless segments.

220 It will be of great interest to also identify $v g$-dependent tissues from non-insect

221 arthropods, such as crustacean species. The $v g$-dependent tissues in the tergum and/or proximal

222 legs may represent crustacean tissues homologous to insect wings, though further analysis will

223 be required to reach a conclusion. Identification of potential wing homologs in non-insect

224 arthropods will have a significant impact on the insect wing origin debate by allowing us to

225 identify the tissues that possibly gave rise to wings in the hexapod lineage. Presence of wing 
226 homologs both in the tergum and the proximal leg would strongly support a dual origin

227 hypothesis.

228 Cooption is always a significant caveat when identifying homologous tissues using a

229 marker gene. For example, it is possible that a tissue unrelated to wings gained $v g$ expression via

230 cooption, which could hinder identification of true wing serial homologs. Using more than one

231 gene as a wing identity marker (such as $n u b$ and $a p$ ) may allow us to identify true wing serial

232 homologs, although it has been shown that even a battery of genes can be coopted together in

233 some contexts (e.g. several leg genes coopted into horn development in Onthophagus beetles

234 [34]). Analyzing more species will also help trace the history of the $v g$-expressing tissues, which

235 will allow us to distinguish newly coopted $v g$-expressing tissues from wing-related tissues. In

236 addition to this standard "more genes, more species" approach, we believe that inducing

237 homeotic transformation is very useful to identify serially homologous structures. As mentioned,

238 Hox genes are often responsible for modifying segmentally repeated structures and providing a

239 unique identity to each segment. Thus, if a $v g$-expressing tissue transforms into a wing upon

240 homeotic transformation, that will strongly support that the tissue in question is serially

241 homologous to wing (see Box 3 for further explanation about serially homologous structures and

242 Hox mutations). Identifying $v g$-expressing tissues, followed by testing the potential of these

243 tissues to transform into a wing upon homeotic transformation will be a powerful way to identify

244 wing serial homologs in various insects.

246 Conclusion

247 Insect wings are a core example of morphological novelty, yet their acquisition remains a

248 biological mystery. A series of evo-devo studies, including our analysis in Tribolium, appears to 
249 point toward a dual origin of insect wings. However, the contribution of evo-devo to the insect

250 origin debate is still in its infancy. Detailed expression and functional analyses for more wing

251 genes in various winged and wingless species will be critical to obtain further insights into insect

252 wing origin from an evo-devo point of view.

253 The evo-devo approach is promising, but has its own limitations. For example, evo-devo

254 analyses do not help determine the selective pressures or the Paleozoic environment that molded

255 the wing from apterygote insect tissues. Evo-devo also does not help reveal the mechanical

256 aspect of the evolution of wings that allowed for efficient flight, nor does it have the ability to

257 reveal the actual shape of the ancient and extinct insects as paleontology can. Instead, evo-devo

258 can provide a new angle to the wing origin debate, which, in combination with other approaches,

259 will provide us with a more comprehensive view of insect wing evolution.

260 The wing origin studies can also impact evolutionary biology in general. Morphological

261 innovation is a fundamental process in evolution, yet the molecular mechanism underlying this

262 process remains elusive. Cooption is often implicated in the evolution of morphologically novel

263 structures [35]. As discussed, we think that the evolution of insect wings might have been

264 facilitated via a distinct mechanism, i.e. "cross wiring" between two developmental systems that

265 relied on a similar set of genes. The application of evo-devo to the study of insect wing origin

266 will broaden the scope of evo-devo by leading to a more comprehensive view of the molecular

267 mechanisms underlying the evolution of morphologically novel structures.

\section{Acknowledgement}

270 We thank Drs. Pick and Extavour for inviting us to contribute to this special issue, the two

271 anonymous reviewers for their thoughtful comments, and members of Tomoyasu lab for 
272 discussion. This work was supported by National Science Foundation (YT: NSF-IOS0950964)

273 and an NSF Graduate Research Fellowship (CCH).

274 


\section{Figure Legends}

\section{Figure 1}

277 Overview of wing origin hypotheses. The locations of two proposed wing origins, terga

278 (blue) and pleura (yellow), in an ancestral insect ground plan. Some articles relevant to

279 this review are also listed. Note that this model is a summary of the two hypotheses and

280 not the reconstruction of an ancestral state of insects. In addition, the presence of

281 pleural exites in some fossil insects is currently under debate among the paleontology

282 community (see $[36,37]$ for the results in opposition to the pleural exites, but also see

283 [38] for a possible confirmation of some of these exites).

285 Figure 2

286 Visual overview of wing serial homologs proposed by classical and evo-devo studies,

287 along with a conceptual framework of the dual origin hypothesis. The locations of

288 proposed wing homologs in various arthropods are indicated by blue (tergal) and yellow

289 (pleural). The elytron resulting from the merger of two wing serial homologs via

290 homeotic transformation is indicated by green. Note that "partially homologous" in the

291 figure refers to a structure being homologous to a part of the wing, and is not meant to

292 imply gradual degrees of homology.

293

294 Box 1: Insect body plan

295 Insects have segmented bodies organized into three distinct sections (or tagma), namely head, 296 thorax and abdomen (A). All locomotion appendages (legs and wings) are associated with the 297 thorax, which is composed of three segments (T1, T2, and T3). Generally, insects possess two 
298 pairs of wings, each on T2 and T3. Although T1 possesses a pair of walking legs, it is "wingless"

299 in all extant insects. Abdominal segments are generally appendage-less, with the exception of

300 some appendages retained in basal orders (such as Collembola) or secondarily acquired

301 appendages in some insect lineages [2].

302 Dorsoventrally, the insect thoracic body wall can be subdivided into three distinct

303 regions; dorsal, lateral, and ventral. The dorsal body wall is composed of a large plate called the

304 notum or thoracic tergum. The lateral portion consists of several pleural plates collectively

305 referred to as the pleuron. The ventral body wall is also often sclerotized and forms the sternum

306 (B). The pleural plates are thought to have stemmed from ancestral proximal leg segments that

307 have fused into the body wall of extant insects (B) [39]. Recent molecular analyses also support

308 the proximal leg segment origin of the pleural plates [22,40,41].

309

\section{Box 2: History of the wing origin debate}

311 Throughout the history of the insect wing origin debate, the popular opinion has shifted between

312 variations of the two prominent hypotheses without reaching any consensus. The first mention of

313 a possible insect wing origin in the literature appears to be by Oken in $1809[3,6,42,43]$, which

314 predates the Darwinian era. In his 1809 publication, Oken claimed that insect wings were

315 analogous to tracheated gills of aquatic arthropods $[44,45]$. Despite the fact that there was no

316 concept of evolution at the time, Oken proposed that insect wings and arthropod gills share some

317 similarity (although he also claimed that the insect wing and the bird feather are related, which is

318 completely false). This idea was expanded to explain that ancestral wings are derived from

319 pleural associated tracheal gills or tracheated gill accessory structures (gill plates) (reviewed in

$320[17,42,43,46])$. A shift away from a pleural origin of wings came with Müller in 1875. Müller 
321 observed that the thoracic lobes of immature termites resemble wings, but are not initially

322 tracheated and therefore cannot be of tracheal origin (mentioned in $[17,42,43]$ ). This marked the

323 early beginning of the reign of the paranotal hypothesis, which was expanded and supported by

324 many scientists $[11,12,17,47]$. In 1978, through examination of Paleozoic pterygote nymphs,

325 Kukalova-Peck proposed that wings are of subcoxal (pleural) origin. Later she amended this

326 hypothesis to link the origin of wings to the exite of a hypothetical proximal-most segment of the

327 ancestral arthropod leg (termed epicoxa) [14]. Although the presence of pleural exites in fossil

328 insects has been under debate [36-38], this exite hypothesis gained momentum when an evo-

329 devo study provided evidence supporting the homology between crustacean exites and insect

330 wings [18].

332 Box 3: Serial homology and Hox mutant analysis in insects

333 Serial homology: Segmentally organized bodies of insects are a reflection of the ancestral

334 arthropod body plan, which consists of repeats of a fairly uniform segmental unit (A) [48]. Each

335 of these ancestral segments is thought to have possessed a set of common structures, such as a

336 pair of legs. These structures on one segment are considered to be serially homologous to the

337 corresponding structures on the other segment, as they share the same developmental and

338 evolutionary origin.

339 Hox function: Hox genes are region selector genes that provide individuality to the otherwise

340 uniform segments and segmentally repetitive structures [48-50]. Hox achieves this task via at

341 least three distinct modes of action, (i) modification of preexisting structures, (ii) suppression of

342 preexisting structures, and (iii) induction of de novo structures. Through these actions, serially 
343 homologous structures are modified uniquely in each segment. Sometimes the modification is so

344 drastic, that it is difficult to recognize homology based on morphology.

345 Tissue marker genes: Some genes are expressed predominantly in a certain tissue. These genes

346 can be used to identify serial homologs, as serially homologous tissues are expected to share the

347 expression of marker genes. $v g$ is one of the wing marker genes, while Distalless ( $D l l$ ) is often

348 used as a marker for the leg-related identity [51]. Though caution must be taken when identifying

349 serial homologs based on marker genes, as these genes could be co-opted into a new context. An

350 example is $D l l$ expression in the beetle horn [52].

351 Identifying serial homologs: Removing Hox function will allow us to strip away the

352 modifications applied to the serially homologous structures, revealing serial homologs that are

353 otherwise morphologically distinct and difficult to recognize. In addition, marker genes will be

354 useful to gain more information regarding the mode of Hox action, and also to determine the

355 precise cell population that is transformed and/or ectopically induced in Hox mutations. Some

356 potential outcomes when Hox function is removed are as follows:

357 - Transformation of one structure to another. This happens when Hox acts to modify the

358 structure (Hox action 1), thus these two structures are likely serially homologous. Insect

359 mouthparts and legs are in this category (B) (reviewed in [48]). These leg serial homologs

360 share $\mathrm{Dll}$ marker gene expression, further supporting their serial homology.

361 Induction of ectopic structures. This happens when Hox acts as a suppressor (Hox action

362 2). The absence of leg serial homologs in the abdominal segments belongs to this category

363 (B) [48]. A key difference compared to the above transformation is that there are no $\mathrm{Dll}$

364 expressing cells in the abdomen unless Hox is removed. 
- Loss of the structure examined. This happens when Hox itself acts as an inductive signal

366 for the structure (Hox action 3), suggesting that the structure was evolved de novo, and

367 that there is no serial homolog of this structure in other segments. Beetle horns may

368 belong to this category (C) [52].

369 Wing serial homologs: Wings are unique to the two thoracic segments (T2 and T3) in extant

370 insects (D, E). Since there are no apparent wing-like structures in other segments, and removing

371 Hox genes could induce wing formation in these segments, it has been considered that induction

372 of wing-related structures are suppressed by Hox in these segments (Hox action 2, D). However,

373 recent evo-devo studies have revealed that there are some tissues outside of T2 and T3 that

374 express $v g$, a wing marker gene [22,30]. Furthermore, in beetles, these tissues transform into the

375 wing upon Hox mutation. These results suggest that the $v g$-positive tissues in the wingless

376 segments found in beetles are wing serial homologs modified by Hox (thus this is Hox action 1

377 instead of action 2, E). 
Papers of particular interest, published within the period of review, have been highlighted as:

- of special interest

$381 \quad \bullet$ of outstanding interest

1. Grimaldi D, Engel MS: Evolution of the Insects: Cambridge University Press; 2005.

2. Division of Entomology CSIRO: The Insects of Australia; a textbook for students and research workers edn second edition. Carlton, Vic.: Melbourne University Press; 1991.

3. Dudley R: Evolution of Flight and Flightlessness. In The Biomechanics of Insect Flight. Edited by: Princeton Unversity Press; 2000:261-301.

4. Kukalova-Peck J: Fossil History and the Evolution of Hexapod Structures. In The Insects of Australia: A textbook for students and research workers, edn second. Edited by Naumann ID: Melbourne University Press; 1991:141-179. vol 1.]

5. Grimaldi D, Engel MS: Fossil Insects. In Evolution of the Insects. Edited by: Cambridge University Press; 2005:42-92.

392 6. La Greca M: Origin and evolution of wings and flight in insects. Bolletino di zoologia 1980, 47:sup1:65-82.

7. Labandeira CC, Beall BS, Hueber FM: Early Insect Diversification: evidence from a Lower Devonian bristletail from Quebec. Science 1988, 242:913-916.

8. Labandeira CC: Rise and Diversification of Insects. In Palaeobiology I/ Edited by Briggs DEG, Crowther PR: Wiley-Blackwell; 2001:82-88.

9. Misof B, Liu S, Meusemann K, Peters RS, Donath A, Mayer C, Frandsen PB, Ware J, Flouri T, Beutel RG, et al.: Phylogenomics resolves the timing and pattern of insect evolution. Science 2014, 346:763-767.

10. Quartau JA: An overview of the paranotal theory on the origin of the insect wings. Publicações do Instituto de Zoologia "Dr. Augusto Nobre" Faculdade de Ciencias do Porto 1986, 194:1-42.

404 -This article comprehensively summarizes the arguments for both tergal and pleural wing origin 405 at a time just prior to the use of evo-devo to study wing origin.

406 11. Rasnitsyn AP: A Modified Paranotal Theory of Insect Wing Origin. Journal of $407 \quad$ Morphology 1981, 168:331-338.

408 12. Hamilton KGA: The insect wing, Part 1. Origin and development of wings from notal lobes. Journal of the Kansas Entomological Society 1971, 44:421-433.

410 13. Grimaldi D, Engel MS: Insects Take to the Skies. In Evolution of the Insects. Edited by: $411 \quad$ Cambridge University Press; 2005:155-187. 
14. Kukalova-Peck $\mathrm{J}$ : Origin of the insect wing and wing articulation from the arthropodan leg. Canadian Journal of Zoology 1983, 61:1618-1669.

-The revised exite theory proposed in this article sparked a reconsideration of pleural tissue involvement in insect wing evolution.

15. Kukalova-Peck J: Phylogeny of Higher Taxa in Insecta: Finding Synapomorphies in the

16. Kukalova-Peck J: Origin and evolution of insect wings and their relation to Extant Fauna and Separating Them from Homoplasies. Evol Dev 2008, 35:4-51. metamorphosis as documented by the fossil record. Journal of Morphology 1978, 156:53-125.

\section{Crampton G: The Phylogenetic Origin and the Nature of the Wings of Insects} According to the Paranotal Theory. New York Entomological Society 1916, 24:1-39.

18. Averof M, Cohen SM: Evolutionary origin of insect wings from ancestral gills. Nature 1997, 385:627-630.

- This article is the first to apply evo-devo to the insect wing origin debate and was influential in changing the popular opinion from a tergal origin to a pleural origin.

19. Cohen B, McGuffin ME, Pfeifle C, Segal D, Cohen SM: apterous, a gene required for imaginal disc development in Drosophila encodes a member of the LIM family of developmental regulatory proteins. Genes Dev 1992, 6:715-729.

20. Ng M, Diaz-Benjumea FJ, Cohen SM: Nubbin encodes a POU-domain protein required for proximal-distal patterning in the Drosophila wing. Development 1995, 121:589599.

21. Niwa N, Akimoto-Kato A, Niimi T, Tojo K, Machida R, Hayashi S: Evolutionary origin of the insect wing via integration of two developmental modules. Evol Dev 2010, 12:168-176.

- This is the first evo-devo study to perform expression analyses for wing genes in basal insects.

22. Clark-Hachtel CM, Linz DM, Tomoyasu Y: Insights into insect wing origin provided by functional analysis of vestigial in the red flour beetle, Tribolium castaneum. ProC Natl Acad Sci U S A 2013, 110:16951-16956.

- This article identifies tergal and pleural wing serial homologs in T1 of Tribolium, and provides the first functional evidence for a dual origin of insect wings.

23. Baena-Lopez LA, Garcia-Bellido A: Genetic requirements of vestigial in the regulation of Drosophila wing development. Development 2003, 130:197-208. and Scalloped proteins act together to directly regulate wing-specific gene expression in Drosophila. Genes Dev 1998, 12:3900-3909.

25. Carroll S, Grenier JK, Weatherbee SD: From DNA to Diversity edn second edition: Blackwell publishing; 2005. 
26. Lewis EB: A gene complex controlling segmentation in Drosophila. Nature 1978, 276:565-570.

27. Weatherbee SD, Halder G, Kim J, Hudson A, Carroll S: Ultrabithorax regulates genes at several levels of the wing-patterning hierarchy to shape the development of the Drosophila haltere. Genes Dev 1998, 12:1474-1482.

28. Tomoyasu $\mathrm{Y}$, Wheeler SR, Denell RE: Ultrabithorax is required for membranous wing identity in the beetle Tribolium castaneum. Nature 2005, 433:643-647.

29. Carroll SB, Weatherbee SD, Langeland JA: Homeotic genes and the regulation and evolution of insect wing number. Nature 1995, 375:58-61.

30. Ohde T, Yaginuma T, Niimi T: Insect morphological diversification through the modification of wing serial homologs. Science 2013, 340:495-498.

- This article identifies wing serial homologs in T1 and the abdomen of a Tenebrio beetle, signifying the use of wingless segments in the investigation of wing origin.

31. Prud'homme B, Minervino C, Hocine M, Cande JD, Aouane A, Dufour HD, Kassner VA, Gompel N: Body plan innovation in treehoppers through the evolution of an extra wing-like appendage. Nature 2011, 473:83-86.

-This article challenges a classic view regarding the identity of the treehopper helmet, proposing that it is a wing homolog. But see [32] and [33] for an alternative interpretation.

32. Miko I, Friedrich F, Yoder MJ, Hines HM, Deitz LL, Bertone MA, Seltmann KC, Wallace MS, Deans AR: On dorsal prothoracic appendages in treehoppers (Hemiptera: Membracidae) and the nature of morphological evidence. PLOS ONE 2012, 7:e30137.

33. Yoshizawa K: The treehopper's helmet is not homologous with wings (Hemiptera: Membracidae). Systematic Entomology 2012, 37:2-6.

34. Moczek AP, Rose DJ: Differential recruitment of limb patterning genes during development and diversification of beetle horns. Proc Natl Acad Sci U S A 2009, 106:8992-8997.

35. Shubin N, Tabin C, Carroll S: Deep homology and the origins of evolutionary novelty. Nature 2009, 457:818-823.

36. Bethoux O, Briggs DEG: How Gerarus lost its head: stem-group Orthoptera and Paraneoptera revisited. Systematic Entomology 2008, 33:529-547.

37. Boxshall GA: The evolution of arthropod limbs. Biological Reviews 2004, 79:253-300.

38. Haug JT, Haug C, Garwood RJ: Evolution of insect wings and development - new details from Palaeozoic nymphs. Biol Rev Camb Philos Soc 2014.

39. Snodgrass RE: The Thorax. In Principles of Insect Morphology. Edited by: Cornell University Press; 1935:157-192.

40. Coulcher JF, Edgecombe GD, Telford MJ: Molecular developmental evidence for a subcoxal origin of pleurites in insects and identity of the subcoxa in the gnathal appendages. Sci Rep 2015, 5:15757. 
41. Linz DM, Tomoyasu Y: RNAi screening of developmental toolkit genes: A search for novel wing genes in the red flour beetle Tribolium castaneum. Dev Genes Evol 2015, 218.

42. Wigglesworth VB: Evolution of insect wings and flight. Nature 1973, 246:127-129.

43. Wigglesworth VB: The evolution of insect flight. Symposia of the Royal Entomological Society of London 1976, 7:255-269.

495 44. Oken L: Lehrbuch der Naturphilosophie, vol 1-3; 1809-1811.

496 45. Oken L: Elements of Physiophilosophy: Ray Society; 1847.

497 -This manuscript is the English translation of [39]. The author attempts to make comparisons between various organisms and is the first to speculate on an origin of insect wings.

46. Woodworth CW: The wing veins of insects. University of California publications technical bulletins 1906, 1:1-152.

47. Snodgrass RE: The Wings. In Principles of Insect Morphology. Edited by: Cornell University

503

504

48. Hughes CL, Kaufman TC: Hox genes and the evolution of the arthropod body plan. Evol

49. Angelini DR, Kaufman TC: Comparative developmental genetics and the evolution of arthropod body plans. Annu Rev Genet 2005, 39:95-119.

50. Pearson JC, Lemons D, McGinnis W: Modulating Hox gene functions during animal body patterning. Nat Rev Genet 2005, 6:893-904.

51. Cohen SM: Specification of limb development in the Drosophila embryo by positional cues from segmentation genes. Nature 1990, 343:173-177. 


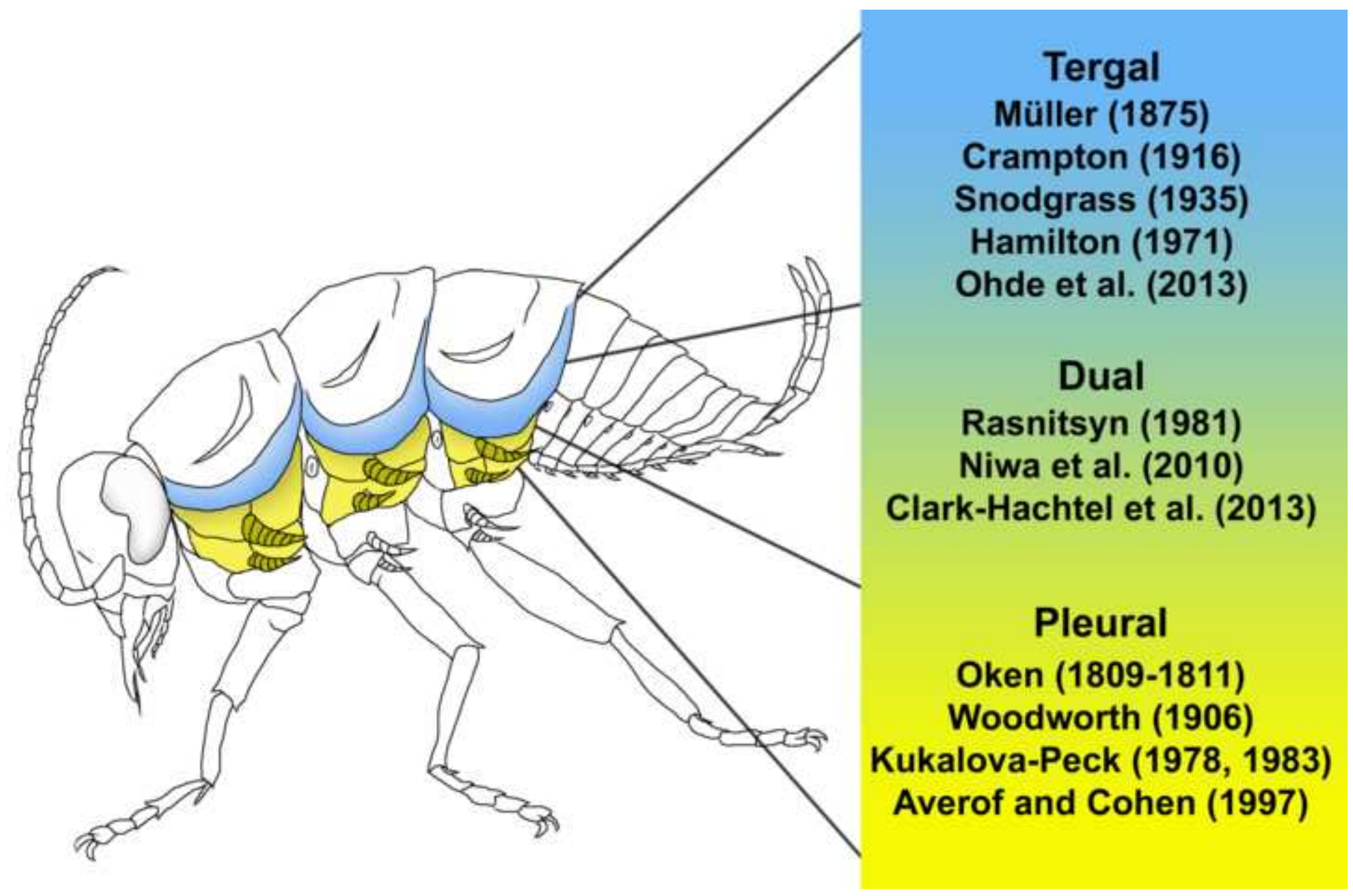


Figure 2

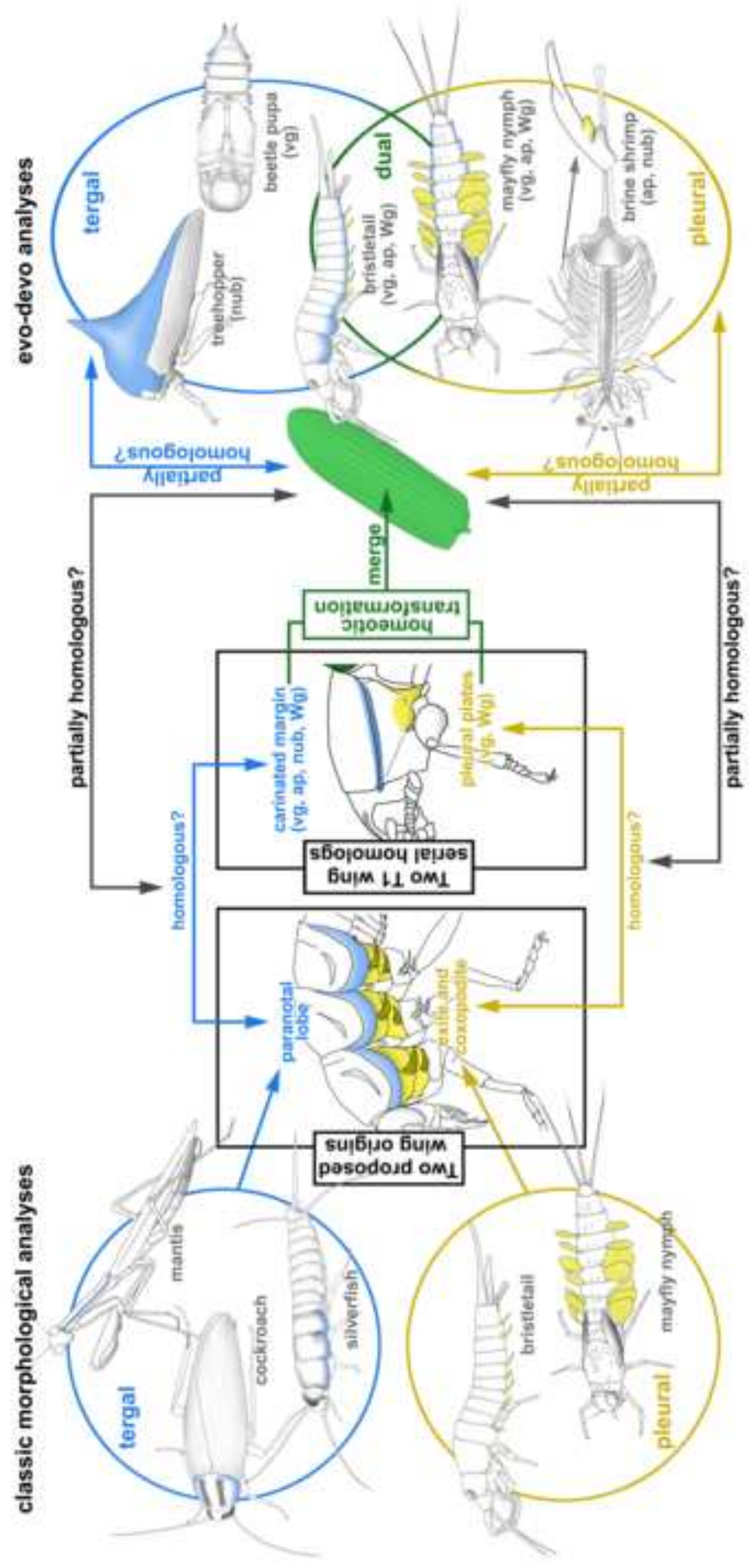


A

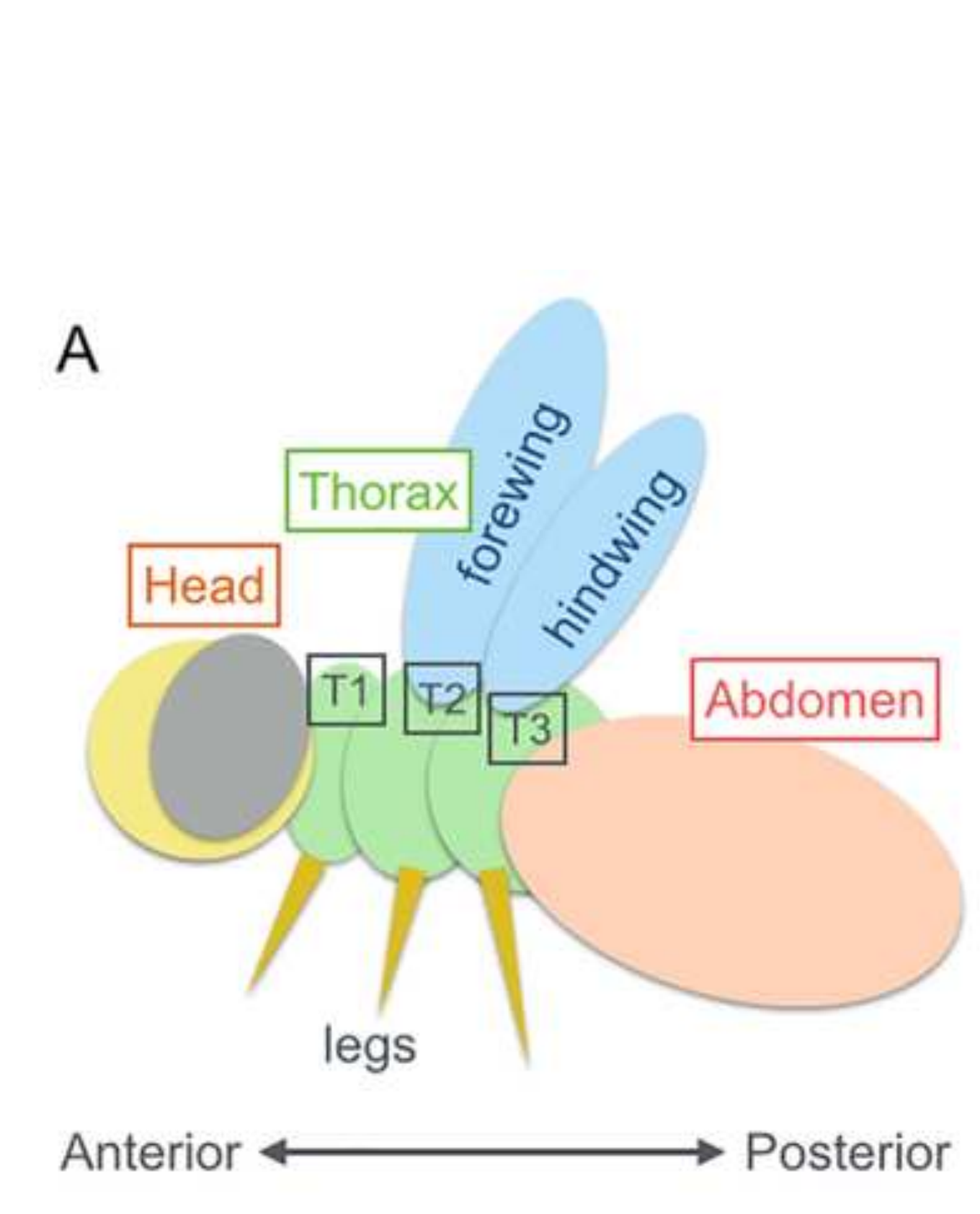

Anterior $\longleftrightarrow$ Posterior legs

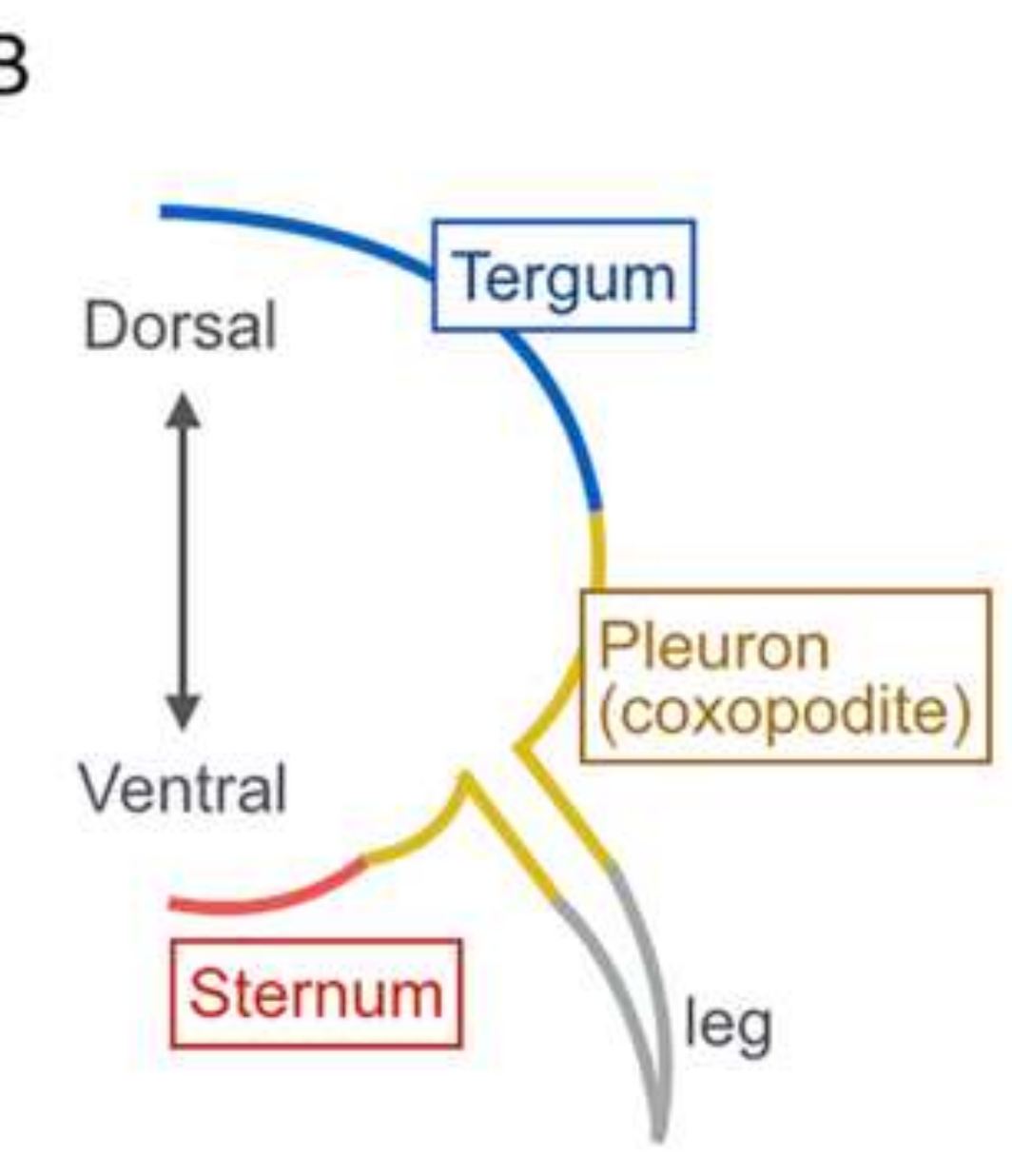

\section{B}

.



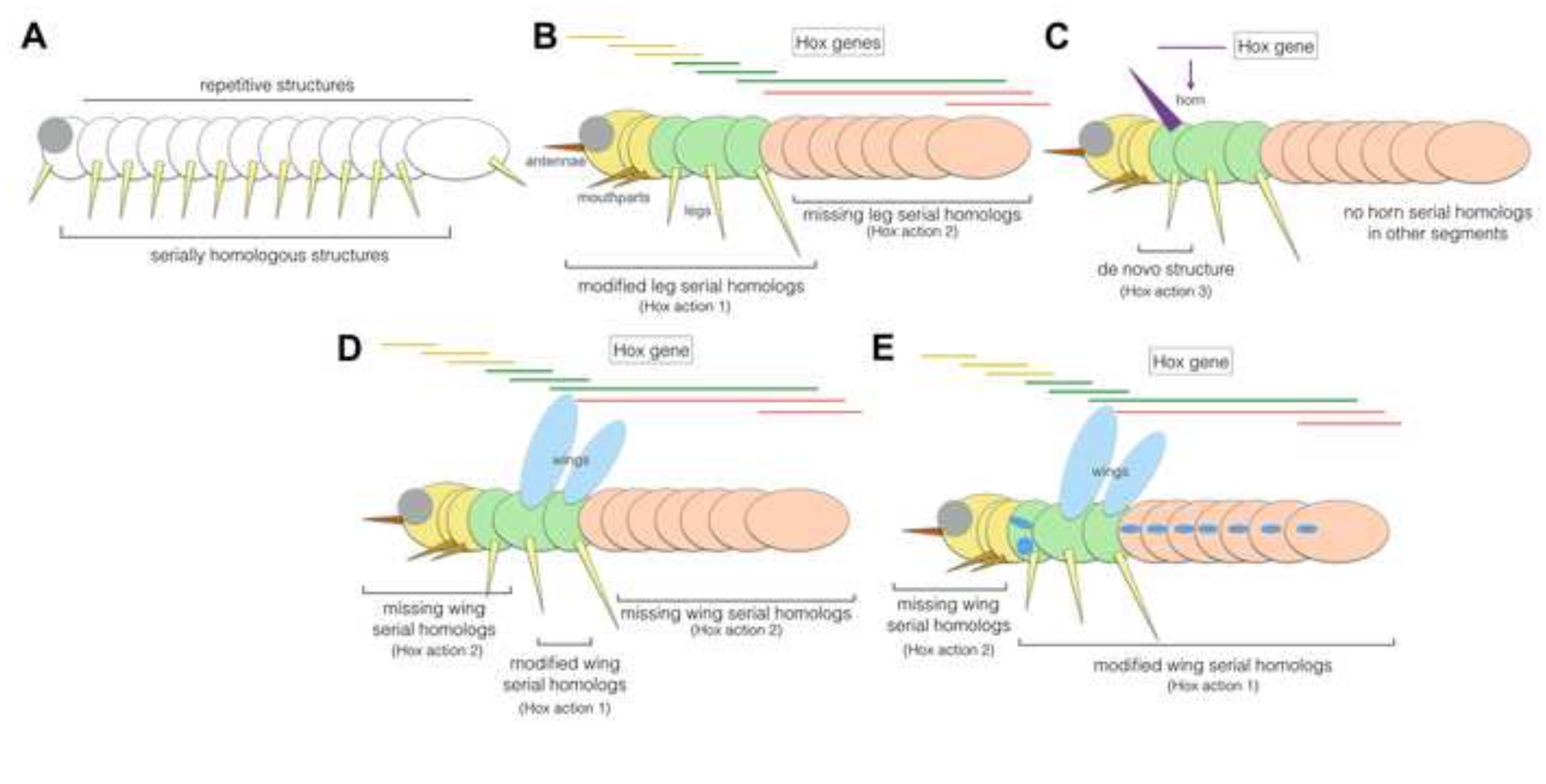

\section{Box 3}

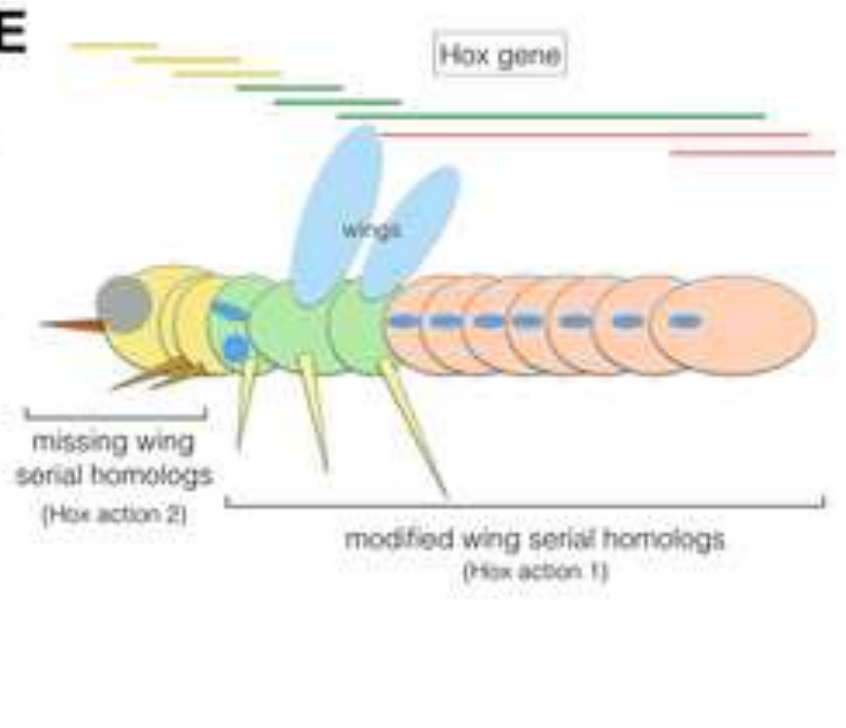

